\title{
Analytical methods for the characterization of surface finishing in bricks
}

\author{
I. Nardini*, E. Zendri, G. Biscontin, A. Brunetin \\ Department of Environmental Sciences, Ca' Foscary University of Venice, Via Torino 155/B, 30174 Venice, Italy \\ Received 24 February 2006; received in revised form 20 June 2006; accepted 21 June 2006 \\ Available online 27 June 2006
}

\begin{abstract}
The recent restoration works of Santo Stefano Church Façade (XV century) in Venice have shown traces variously saved of different kind of surface finishes. These finishes were found on the brick's surface both in the masonry and in the decorative elements.

Different brick's surface and decorative tile samples were investigated using several techniques: optical microscopy, scanning electronmicroscopy, thermal analysis, infrared spectroscopy and reflectance Fourier transform infrared microspectroscopy.

The evaluation of the reached results was used to understand the decorative techniques and to recognize the material employed.

(C) 2006 Elsevier B.V. All rights reserved.
\end{abstract}

Keywords: Brick; Surface; Finishing; Fourier transform infrared spectroscopy; Thermal analysis

\section{Introduction}

In Venice the masonries are particularly subjected to the capillarity rise of water and therefore to the salts crystallization that interest the first 2-3 m of the masonry surface. This phenomenon causes a type of decay for which the Venetian operate with a substitution of the materials, denominated "scuci e cuci", erasing the historical information of the manufactures naturally accessible to the observer. Frequently the restoration intervention gives the possibility to examine the masonry in this area of the buildings and permits to individualize the original finishes that cannot be observed from the ground because of their little dimensions; besides the identification of some superficial finishings characterizing wide architectonical elements may induce to put forward hypotheses on the execution technique. This case is verified during the restoration operation of Santo Stefano Church in Venice. At sight the façade of the church is made by bricks and the comparison between the documentation of the building with the observations of the church's structure leads to consider the actual façade the result of an important intervention of rearrangement. The construction of Santo Stefano church started at the beginning of 1300 A.D. and finished only after a century realizing a typical example of religious architecture in late Gothic style [1]. In 1900 and in 1970 the Church underwent some

\footnotetext{
* Corresponding author. Tel.: +39 0412346737; fax: +39 0412346729.

E-mail address: nardini@unive.it (I. Nardini).
}

operations of restoration and maintenance also involving the masonry façade only until $2.5 \mathrm{~m}$ width $[2,3]$. Some observations near the surface of the façade have put in light two interesting situations:

- The baked elements (bricks, tiles and mouldings) that delimit the openings of the central zone, like windows and rose window, present wide smooth and regular areas in which colourings apparently applied directly on support appear. The interesting aspect about this type of surfaces, denominated type A, come from the hypothesis that they could be original traces of colouring applied by an oil binder on smooth bricks during the XIV century. Often the use of this finishing technique has been supposed above all in according to many information reported in some historical documents of the XV century [4].

- Many traces of red and white coloured plastering (regalizier), denominated type $\mathrm{B}$, reproducing the drawing of the bricks and the joint mortars are present on the masonry of the church.

\section{Experimental}

The work regards the investigation of 29 samples of type A collected by the baked elements adorning the superior openings on the façade in order to recognize both the decorative techniques employed on baked materials of some particular architectonical elements and to stabilize their possible originality. 


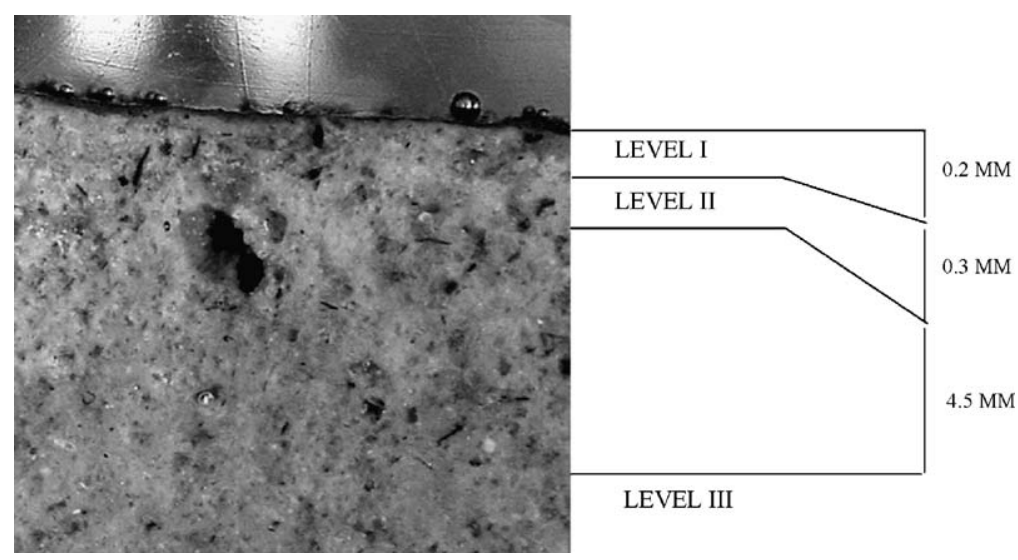

Fig. 1. Cross section with the indication of the collecting points, denominated levels I-III. The level III fragments are collected at a distance of $5 \mathrm{~mm}$ from surface considering this point representative of the bulk.

The cross sections of all samples were observed by a stereomicroscopy Olympus SZX9 and were photographed by digital camera Olympus C-5050. For some representative samples thin sections were prepared to study the petrographic characteristics by an Olympus BX41 microscope.

Some cross-sections were investigate by the scanning electron microscope Jeol JSM 5600 LV equipped with an electronic microprobe for the revelation of the fluorescence $\mathrm{X}$ radiation (SEM/EDX).

Portions of samples collected in different depth along the cross section were collected in order to evidence possible compositional differences. The range of depth, named level I-III, can be defined as reported in Fig. 1. The spectra were registered by a Nexus Nicolet spectrometer (FT-IR) equipped with a DMCS detector. In some cases the reflectance Fourier transform infrared microspectroscopy made by a Continum $\mu$ m Nicolet microscope with a MCT detector was employed in order to obtain further information about the nature of the compounds. The spectral range investigated in these experiments covered a domain from 4000 to $650 \mathrm{~cm}^{-1}$ with a space resolution of $50 \mu \mathrm{m} \times 50 \mu \mathrm{m}$.

On the samples collected in different depth were also carried out the thermogravimetry and the differential scanning calorimetry in simultaneous (TG/DSC) by a Netzsch STA 409/C instrument using a scanning rate of $10^{\circ} \mathrm{C} \mathrm{min}^{-1}$ with an air flow of $60 \mathrm{~mL} \mathrm{~min}^{-1}$ and in the temperature range of $50-1000^{\circ} \mathrm{C}$.

\section{Results and discussion}

The stereomicroscopic observations of cross sections have revealed a substantial uniformity of the bulk mixture, light and with hue changing from yellow to light brown. This chromaticity permits to suppose the cooking was carried out at low temperature also because the mixture includes relevant quantities of calcium carbonate. The mixtures contain many aggregates of different nature: quartz, hematite, red brick fragments; the granulometry varies from very fine sand $(63-125 \mu \mathrm{m})$ to fine sand $(125-250 \mu \mathrm{m})$, while there are not aggregates with dimension above $400 \mu \mathrm{m}$.
The red colour finishings directly adhere on support surface and their thickness is between 20 and $40 \mu \mathrm{m}$. The absence of carbon traces and gypsum crusts between support and finishing permits to suppose the finishing was contextual at the working of the baked elements. Fourteen samples show thin coloured finishing under a compact black patina; in others the finishing is disappeared and patinas result to adhere to decayed support.

The petrographical thin sections observations have permitted to recognize a stratigraphical sequence:

- Coloured thin and compact layer ascribable to the use of colouring earths like red ochre.

- Compact layer devoid of aggregates with a thickness of $100-300 \mu \mathrm{m}$; the presence of this type of layer can be attributed both to the mechanical action exercised during the element manufacture and to an intentional covering like engobe [5]. The no+ dimensions of this compact layer permit to retain more credible the supposition of an engobe finishing in order to obtain a smooth surface of the moulded elements [6].

- Support with many aggregates like quartz, different mineral silicates and aggregates of metamorphic carbonatic rocks: the presence of carbonatic species indicate the cooking temperature was under $750{ }^{\circ} \mathrm{C}$. Cracks and porosity in mixtures indicate shrinkage phenomenon and development of gases during the cooking phase. Into porous the presence of micritic calcite of neo-formation is evident.

The scanning electron microscopy confirms these morphological information and evidences the compact layer under the finishing (Fig. 2). Further information are collected with the map of the elements on the cross section. The distribution of calcium element is homogeneous along the profile of the section. The coloured finishing does not report a calcium concentration greater than the concentration registered on the lower layers and it does not permit to indicate the calcium carbonate as binder used to spread the colour. No samples reports phosphorous element generally associated to the use of proteinaceous binder. On the contrary sulphur is always present and it is generally located in a zone into support with different width $(0.5-1 \mathrm{~mm})$ far away 


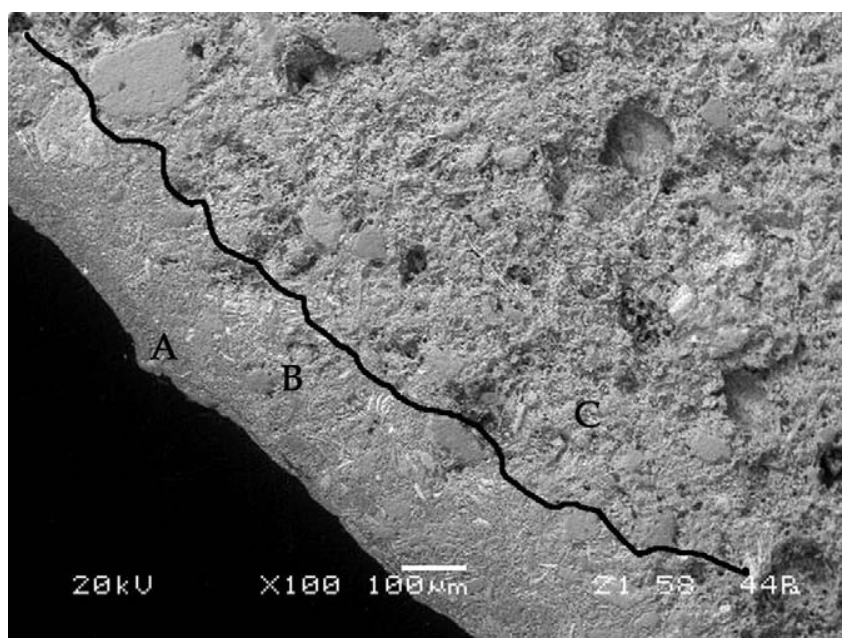

Fig. 2. Secondary electron SEM image of a sample. At this magnification $(100 \times)$ the finishing surface (A) does not result morphologically discernible from the layer below characterized by a compact support with fine aggregates particles (B). The mixture (C) is more porous than the support layer and shows aggregates with dimension above $100 \mu \mathrm{m}$.

$100-300 \mu \mathrm{m}$ from the surface. The punctual analysis on the surfaces has not revealed metal elements, except iron to which is attributable the colour.

The FT-IR spectroscopy has permitted to stabilize at which compounds the presence of calcium and sulphur elements revealed with SEM analysis can be ascribed. The spectra show whewellite $\left(1626,1381,1317\right.$ and $\left.781 \mathrm{~cm}^{-1}\right)$, gypsum $(3540$, $3410,1680,1620,1140,1115,670$ and $\left.602 \mathrm{~cm}^{-1}\right)$ and calcium carbonate in the form of calcite $\left(1795,1440,875\right.$ and $\left.710 \mathrm{~cm}^{-1}\right)$ with also the presence of quartz $(1165,1090,800,780,694,520$ and $400 \mathrm{~cm}^{-1}$ ) and silicatic minerals; no organic compounds were identified. The comparison between the intensity of the characteristic peaks correlated to the different compounds permits an analysis of the distribution of the compounds along the section (Fig. 3):

- whewellite is present exclusively in level I, there are no traces of it in level III;

- gypsum is particularly present in level II with low concentration in some cases in level I;

- calcite is absent in level I, while it is always present in level II.

The concentration profile of these compounds agrees and justifies the concentration profile obtained by SEM mapping. Some reflectance FT-IR micro analysis (Figs. 4 and 5) were carried out to verify if the superficial composition coincide with the composition of level I. The results have confirmed the diffuse presence of whewellite in coloured surfaces and gypsum on porosity.

The thermogravimetric and the calorimetric analyses were carried out both to understand the nature of the binder used during the colouring phase and its correlation with the presence of the whewellite and to quantify the compounds identified by FTIR spectroscopy. Fig. 6 shows a typical registered thermogram: endothermic peaks at 125 and $160^{\circ} \mathrm{C}$ correlated to mass changes are attributable to the crystallization water loss of gypsum and whewellite respectively [7]. The little temperature difference

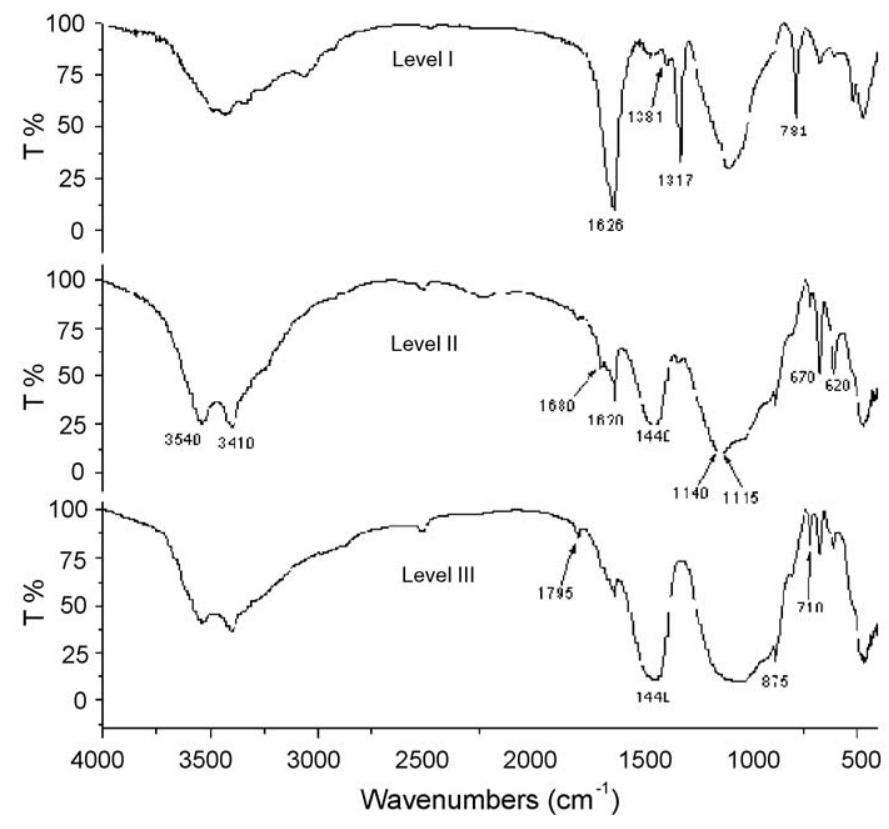

Fig. 3. FT-IR spectra comparison of sample collected from levels I-III. Level I shows the preponderant presence of whewellite while level II displays the simultaneous presence of gypsum and calcite. In level III the calcite becomes the predominant compound.

between the two transformations involves a scanty resolution of the peaks and the difficulty to estimate the relative percentage in the cases in which there are gypsum and oxalate hydrated compounds simultaneously. In this case the presence of only oxalate monohydrated species has permitted to evaluate the whewellite quantity through the estimation of $\mathrm{CO}$ developed during the reaction in the range temperature between 400 and $460{ }^{\circ} \mathrm{C}$. The concentration of gypsum in samples was determined subtracting the crystallization water attributable to whewellite from the water loss in the temperature range of $110-180^{\circ} \mathrm{C}$. The oxalate anhydrous mass loss at temperature above $400{ }^{\circ} \mathrm{C}$ is correlated to the decomposition reaction (endothermic):

$$
\mathrm{CaC}_{2} \mathrm{O}_{4} \rightarrow \mathrm{CaCO}_{3}+\mathrm{CO} \uparrow\left(400-500^{\circ} \mathrm{C}\right)
$$

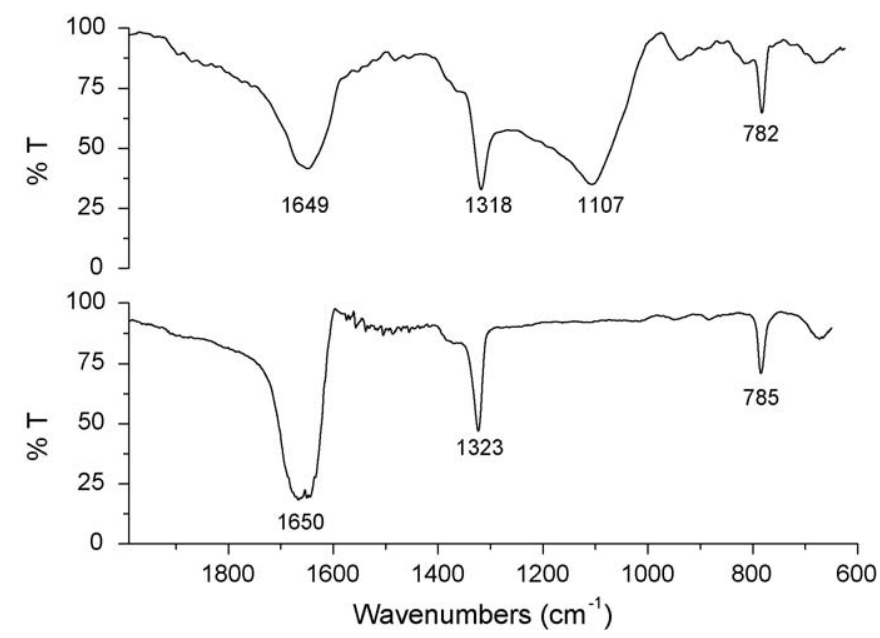

Fig. 4. FT-IR reflectance spectra comparison between the surface of a sample (up) and a whewellite standard (down). 

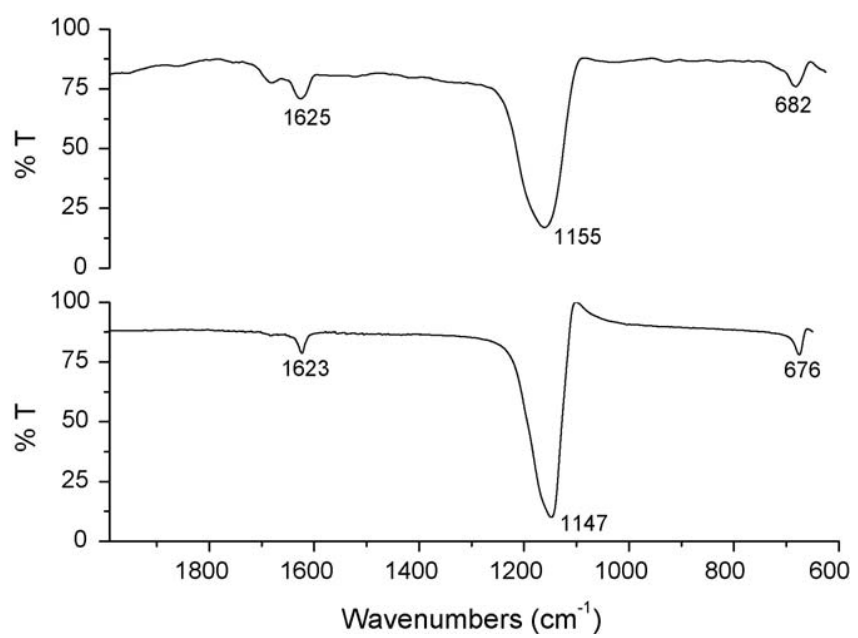

Fig. 5. Micro FT-IR reflectance spectra comparison between the surface of a sample (up) and a gypsum standard (down).

Since the analyses were carried out in air atmosphere the formation of $\mathrm{CO}$ involves its oxidation:

$\mathrm{CO}+(1 / 2) \mathrm{O}_{2} \rightarrow \mathrm{CO}_{2}$

The reaction has got an enthalpy such that only the exothermic peak is registered. The thermal analysis carried out on the calcium oxalate monohydrated standard have not shown the presence of the little exothermic peak $\left(410^{\circ} \mathrm{C}\right)$ at the beginning of the calcium oxalate decomposition like the samples; this phenomenon can be justified because of the presence of impurities. The weight determination of calcite was carried out considering the decomposition reaction of calcium carbonate and making allowance for the calcium carbonate coming from the decomposition of whewellite. The weight comparison has to be considered only indicative because of reduced dimension of levels and the difficulty of a selective collecting. In Table 1 the concentration ranges of the three compounds in the layers are reported: the trend agrees with the FT-IR results.

The thermal analyses permit to exclude the presence of organic substances because calorimetric curves imputable to

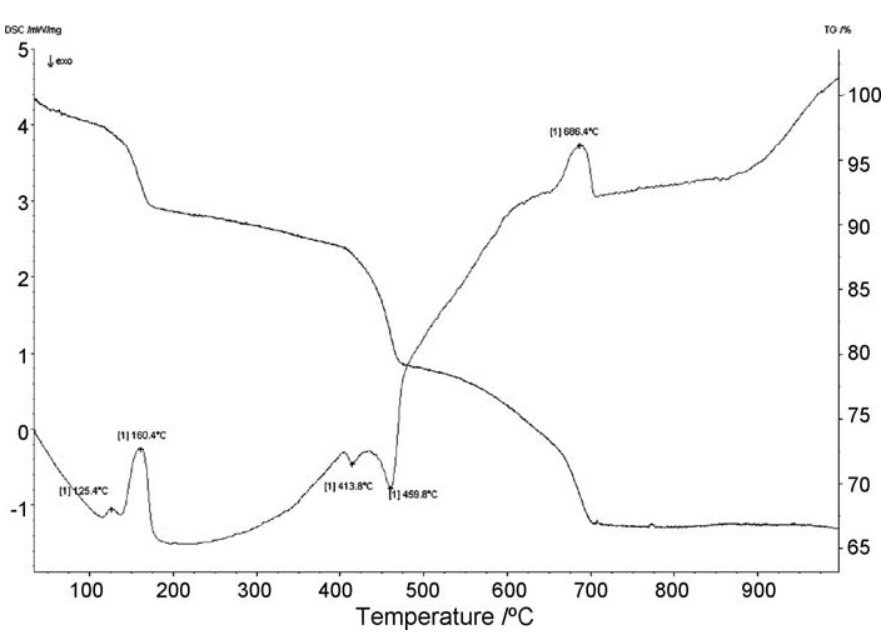

Fig. 6. TG/DSC of a sample coming from level I-decomposition of gypsum, whewellite and calcite.
Table 1

Mean trend of concentration profile of whewellite, gypsum and calcite from surface to inner sample

\begin{tabular}{lllc}
\hline & Whewellite (\%) & Gesso (\%) & Calcite (\%) \\
\hline Level I & $5-40$ & $0-15$ & $0-5$ \\
Level II & $0-5$ & $5-20$ & $10-15$ \\
Level III & 0 & $0-4$ & $10-20$ \\
\hline
\end{tabular}

organic compound were not registered. The TG/DSC analysis highlighted the decomposition of calcite in level III $\left(710-760^{\circ} \mathrm{C}\right)$ that often occurs when the decomposition of calcium carbonate is already in progress as it is possible to verify in thermal curve. So it is possible to distinguish in thermograms a first phase at temperature of about $600{ }^{\circ} \mathrm{C}$ in which the neoformation of micritic calcite starts to decompose and a second phase at temperature up to $700^{\circ} \mathrm{C}$ in which also the metamorphic crystalline calcite present as aggregate in mixture decomposes. These observations according to thin sections information authorize to indicate as superior limit of cooking of the manufactures the temperature of $700^{\circ} \mathrm{C}$. An example of this phenomenon is reported in Fig. 7.

The concentration profile of calcite, whewellite and gypsum can be explained by the information obtained with the different techniques on support and the hypothesis that the decorative technique used in the past on this manufactures was based on the employment of oil substances perhaps mixed with gypsum binding the pigment. The presence of calcite into support is attributable both to the carbonatic component into the clay employed in the mixture and to the calcium carbonate aggregates used like degreasing. The limited presence of calcite in level I is ascribable to the use of a purified clay in the finish layer. In all cases the cross section observation and the chemical analyses lead to the exclusion of lime as pigment binder. The whewellite is difficult to ascribe to phenomenon of deposition of calcium oxalate coming from atmosphere because it is present into the coloured layer and in some cases in a little portion of support but not above the surface with an aspect of a patina. Besides the origin of the oxalate cannot be attributed to biologic action

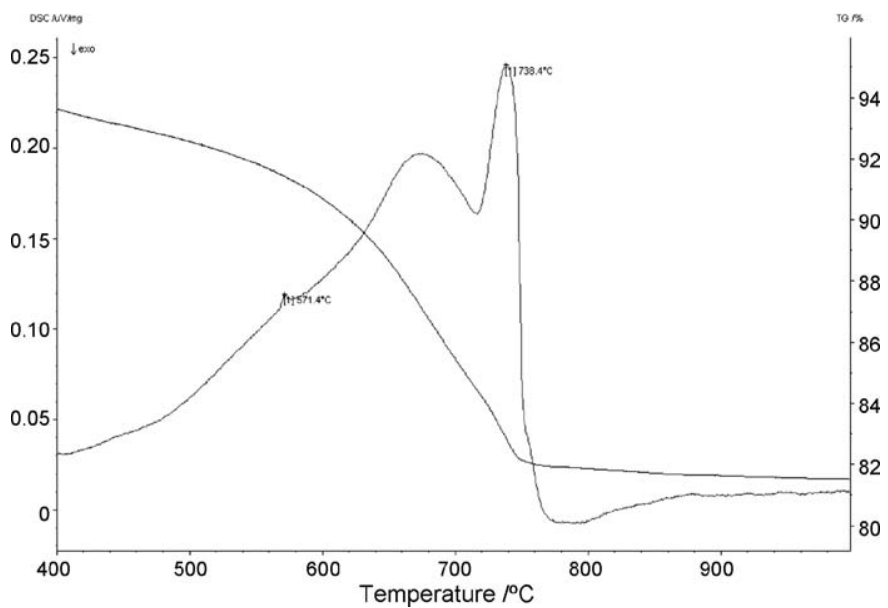

Fig. 7. TG/DSC of a sample coming from level III-decomposition of micritic calcite (first phase) and decomposition of metamorphic calcite (second phase at $738^{\circ} \mathrm{C}$ ). The endothermic peak at $571^{\circ} \mathrm{C}$ is due to the $\alpha \rightarrow \beta$ quartz transition. 


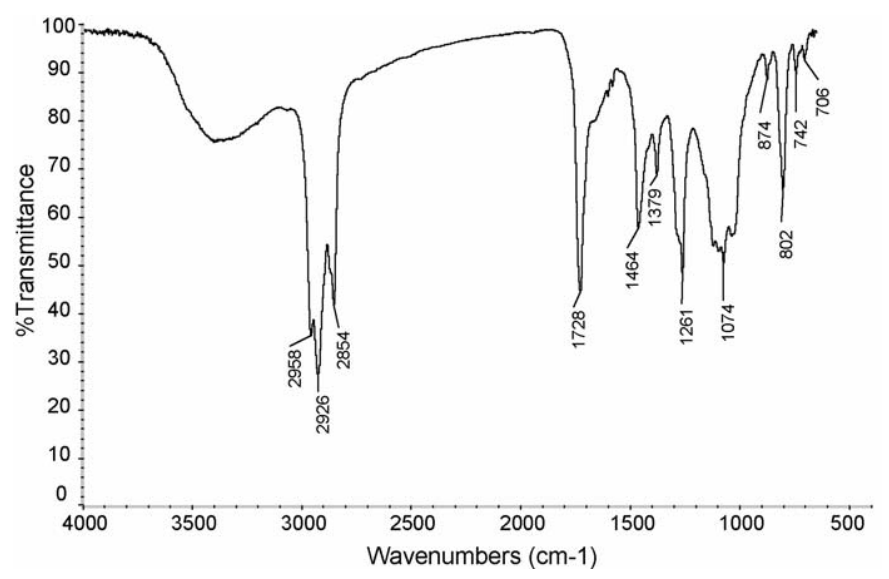

Fig. 8. FT-IR spectrum of the extract from a sample.

because it is not compatible with the good state of conservation of the samples [8-10]. It is proper to suppose the presence of whewellite as the result of decay phenomenon of some organic substances used in the past both as surface protective agent and as binder to draw up the colours. The examination of the lipidic and proteinaceous substances presence was performed on five samples by Soxhlet extraction using a mixture of chloroform/ethanol (2/1, v/v) [11,12]. The FT-IR analysis carried out on the extracts permitted to recognize the presence of organic substances as it is possible to see in Fig. 8. In fact the spectra showed the presence of the aliphatic groups with the $\mathrm{CH}_{3}$ and $\mathrm{CH}_{2}$ asymmetric stretching vibration at 2957 and $2926 \mathrm{~cm}^{-1}$, the symmetric $\mathrm{CH}_{2}$ absorption at $2854 \mathrm{~cm}^{-1}$, the $\mathrm{CH}_{3}$ asymmetric deformation vibration at $1463 \mathrm{~cm}^{-1}$ and the symmetric $\mathrm{CH}_{3}$ deformation vibration at $1379 \mathrm{~cm}^{-1}$. In particular the spectra displayed also the presence of the ester groups with the carbonyl stretching vibration at $1727 \mathrm{~cm}^{-1}$ and the $\mathrm{CO}$ stretching at $1261 \mathrm{~cm}^{-1}$. The absence of phosphorous and phosphates investigated by scanning electron microscopy and FT-IR spectroscopy leads to exclude the use of proteinaceous substances like casein while the hypothesis of the use of oil substances like linseed oil is coherent with the results of this research, with the historical documents and the positive studies about the possibility that oil compounds applied on support containing calcium can form calcium oxalate [13]. The presence of gypsum can be attributable to sulphation process as consequence of the interaction of sulphuric acid with calcite present into support. Besides the high gypsum concentration identified, the concentration profile along the cross section and the absence of gypseous crusts on surface permit to suppose a theory: in fact if the colour was prepared dispersing a pigment and a little quantity of gypsum in linseed oil, it is possible to retain that calcium oxalate is formed at gypsum expense and the released sulphate ions migrate towards the inner support where there is an higher porosity, putting out this zone to sulphation process.

\section{Conclusion}

The different techniques employed for the characterization provide coherent information.
The support of samples reports similar characteristics without evident differences between mixture of different architectonical elements.

From the results of the analyses it is possible to assume that the clay used for the realization of the manufactures came from a clayey rock with a significant percentage of calcite. The mixture is made by adding relevant quantity of aggregates of different nature with the function of degreasing.

The cooking temperature was not superior to $700{ }^{\circ} \mathrm{C}$ because at higher temperature the calcite present into support should be decomposed as it is evidence by thermal analysis.

Between support and coloured layer a thin layer in which the clay results particularly compact and absent of impurity is present; it is attributable to a covering realized with the same clay used for make the mixture but subjected at depurative process. This treatment permits to obtain regular surfaces, with low porosity suited to be decorated.

The technique employed for the decoration of the manufactures is compatible to a technique based on oil binder in which it was probably dispersed gypsum and colouring earths. The morphology of samples and the absence of deposits between the coloured layer and support permit to retain correct the theory that this surfaces are original finishing dating back to fifteenth century.

\section{References}

[1] G. Lorenzetti, in: Lint (Ed.), Venezia e il suo estuario, Trieste, 1999, p. 502

[2] E. De Angelini Baldi, Chiesa di Santo Stefano Promartire, Tip.Emiliana Artigianelli, Venezia, 1992, p. 5.

[3] V.V. Aa, Chiesa di santo stefano, Venezia Restaurata, Milano, Electa, 1986, pp. 164-165.

[4] M. Piana, L'architettura gotica veneziana, Istituto Veneto Arti e Mestieri, Venezia, 2001, pp. 61-70.

[5] B. Fabbri, in: all'Insegna del Giglio (Ed.), Atti del convegno: 'Il Cotto tra storia e ricerca', Ferrara, 1995, pp. 119-118.

[6] G. Berti, T. Mannoni, Scienze in Archeologia, 1988, pp. 89123.

[7] R.C. Mackenzie, R. Mitchell, Differential Thermal Analysis, vol. 2, Academic Press, London, 1978, pp. 622-623.

[8] O. Salvadori, M. Realini, Atti del convegno: 'The oxalate films in the conservation of works of art', Milano, 1996, pp. 335351.

[9] C. Urzì, W. Krumbein, J. Lyalikova, U. Wollenzien, M. Zagari, Microbiological investigation of marbles exposed to natural and anthropogenic influences in northern and southern climate, in: Proceeding of the III International Symposium on the Conservation of Monuments in the Mediterranean Basin, Venice, 1994, pp. 297-304.

[10] W.E. Krumbein, K. Petersen, H.-J. Schellnhuber, On the geomicrobiology of yellow, orange, red, brown and black film and crusts developing on several different types of stone and objects of art, in: Proceedings of the International Symposium "The Oxalate Films: Origin and Significance in the Conservation of Works of Art", Milano, 1989, pp. 337347.

[11] M. Camaiti, C. Fommei, M. Giamello, G. Sabatini, A. Scala, Atti del convegno: 'The Oxalate Films in the Conservation of Works of Art', Milano, 1996, pp. 287-298.

[12] G. Torracca, Solubility and Solvents for Conservation Problems, ICCROM, 1984, pp. 40-47.

[13] P. Cremonesi, L'uso dei solventi organici nella pulitura di opere policrome, Il prato, 2004, pp. 21-32. 